\title{
Response Evaluation Criteria In Lymphoma 2017
}

National Cancer Institute

\section{Source}

National Cancer Institute. Response Evaluation Criteria In Lymphoma 2017. NCI

Thesaurus. Code C159617.

The 2017 update to an international-consensus set of response criteria for lymphoma first established in 1999. These guidelines were refined in 2007 to incorporate assessment of tumor metabolism by [18F]2-fluoro-2-deoxy-D-glucose positron emission tomography (FDG-PET) and further refined in 2017 to incorporate a scoring system to enhance the reproducibility of the interpretation and reporting of FDG-PET results, and to update the recommended procedures for staging evaluation. 